\title{
Puntos de Revisión. Libertad, dignidad e inseguridad en la misma fosa.
}

Jorge Pesqueira Ancheta*

Es una realidad que, tanto funcionarios públicos como ciudadanos, debemos aceptar: estamos viviendo en una época de paranoia ante la muy en boga inseguridad, lo cual lleva a tomar medidas con tildes dic tatoriales y por demás lesivas de derechos humanos.

Sin ser excluyentes (es decir, no aceptando que sea el único derecho fundamental transgredido), este trabajo tratará lo anterior relacionado a la libertad de tránsito, consagrada básicamente por el artículo 11 de nuestra Constitución general, pero también por los diversos 14으 y 16으, así como, además, por distintos instrumentos intemacionales de derechos humanos.

Haciendo referencia a estos últimos, y adentrándonos más en el punto medular de esta comunicación, cabe remontarse al pilar de los mismos: la Declaración de los Derechos del Hombre y del Ciudadano de 1789, la cual tenía como unos de sus principales objetivos teminar con la subordinación a un gobiemo absolutista y el reconocimiento de la libertad general por parte del Estado. “Algunos consideran que el artículo 70 de aquel celebémimo antecedente en materia de derechos humanos alude, a contrario sensu, a la libertad de movimiento al prohibir los arrestos o detenciones sin justificación legal" contribuye Andrade Sánchez.

Sin duda, la manifestación más indignante, indiscriminada y arbitraria es la consistente en los puntos de revisión, comúnmente denominados "retenes". Vista la eventual organización de los mismos, podría parecer que se encuentran legitimados por nuestro sistema nomativo.

Es en tomo a esto último que se han gestado opiniones sobremanera diversificadas. Para comenzar con la personal, haremos 
referencia al artículo 11 constitucional. De la lectura del mismo se desprenden algunas limitaciones expresas a la libertad de tránsito, a saber:

a) Facultades de la autoridad judicial. Entre las cuales, encontramos las de ordenar un arresto, una aprehensión o sujeción a proceso; hasta la emisión de sentencia condenatoria en la que se restrinja, en alguna de sus formas, la libertad. En ninguna ley orgánica del Poder Judicial encontramos la atribución jurisdiccional de establecimiento de puntos de revisión.

b) Facultades de la autoridad administrativa: que, limitativamente, se citan lo relativo a leyes sobre emigración, inmigración y salubridad general de la república, o sobre extranjeros pemiciosos residentes en el país. Cierto es que las restric ciones de orden administrativo pueden ser más amplias, las enunciadas en esta parte se refieren concretamente a cuestiones sobre extranjería y derecho intemacional, o bien, personas que potencialmente provocanáa una epidemia o un mal de (muy) difícil contención.

En ninguno de los casos anteriores se estima adecuada la instalación de "retenes" ya que sería una restricción a la libertad de tránsito de toda persona que circule por la ubicación de éstos. Asimismo, por las situaciones a que se hace referencia, no es lógico que tales operativos se instalen indistintamente en ciudades o fuera de ellas, partic ipando, sobre todo, corporaciones policíacas de cualquier nivel e, incluso, milita res. Por cierto, la inclusión de éstos últimos, como se verá a continuación, es de lo más antic onstitucional.

Cierta mente el artíc ulo 11 constitucional es el principal en cua nto a libertad de tránsito en el derecho intemo mexicano; sin embargo, como se apuntó antes, no es el único, pues se encuentra respaldado por los numerales 14 y 16 de la misma ley, de los que a continuación extra emos lo siguiente: 
ARTICULO 14.

(...) NADIE PODRA SER PRIVADO DE LA LBERTAD O DE SUS PRO PIEDADES, POSESIONESO DERECHOS, SINO MEDIANTE JUICIO SEGUIDO ANTE LOS TRIBUNALES PREVIAMENTE ESTABLECIDOS, EN EL QUE SE CUMPLAN LAS FORMALDADES ESENCIALES DEL PROCEDIMIENTO Y CONFORME A LAS LEYES EXPEDIDAS CON ANTERIORIDAD AL HEC HO. ARTICULO 16. NADIE PUEDE SER MOLESTADO EN SU PERSONA, FAMIUA, DOMICIUO, PAPELESO POSESIONES, SINO EN VIRTUD DE MANDAMIENTO ESCRITO DE LA AUTORIDAD COMPEIENTE, QUE FUNDE Y MOTIVE LA CAUSA LEG AL DEL PROCEDIMIENTO.

(...) EN LOS CASOS DE DEUTO FLAGRANTE, CUALQUIER PERSONA PUEDE DEIENER AL INDICIADO PONIENDOLO SIN DEMORA A DISPOSICION DE LA AUTORIDAD INMEDIATA Y ESTA, CON LA MISMA PRONTTTUD, A LA DEL MINISTERIO PÚBLCO.

(...)EN TODA ORDEN DE CATEO, QUE SOLO LA AUTORIDAD JUDICIAL PODRA EXPEDIR Y QUE SERA ESCRITA, SE EXPRESARA EL LUGAR QUE HA DE INSPECCIONARSE, LA PERSONA O PERSONAS Q UE HAYAN DE APREHENDERSE Y LOS OBJ ETOS QUE SE BUSCAN, A LO QUE UNIC AMENTE DEBE LMITARSE LA DIUGENCIA (...).

LAS INTERVENCIONES AUTORIZADAS SE AJUSTARAN A LOS REQUISITOS Y UMITES PREVISTOS EN LAS LEYES. LOS RESULTADOS DE LAS INTERVENCIONES QUE NO CUMPLAN CON ESTOS, CARECERAN DE TODO VALOR PROBATORIO.

Ante la imposibilidad de extensión, y a resumidas cuentas, en ninguno de los anteriorescasos se establece la facultad de la autoridad administrativa de seguridad pública o administración de justicia de colocar puntos de revisión indiscriminada. Sin embargo, los últimos dos pámafos del artículo 16 nos llevan a una segunda trasgresión de derechos. La privacidad. Si es posible llegar a la inferencia de que los retenes, por lo menos en la actualidad, tienen como objetivo la reducción (o prevención) de la delincuencia, el paso a seguir por quienes participan en ellos sería encontra objetos relaciona dos con un delito, ya sea con el que se cometa o pueda cometer, o que sea resultado del mismo. Lo anterior necesariamente implica una auscultación tan minuciosa como el encargado quiera... sin una orden judicial de cateo. En este entendido, todo lo que se obtuviere de dicha búsqueda careceńa de todo valor probatorio en un proceso instaura do en contra de quien haya rendido frutos dicha búsqueda. Desafortunadamente, no es así. En la praxis es común ver expedientes que contienen un parte informativo en el que se dice haber detenido a 
una persona o "se procedió" a su revisión por parecer sospechosa (en cualquiera modalidad que una persona pueda parecerlo a juicio del agente).

Remitiéndonos unos párrafos atrás, encontramos la flagrancia, figura que permite a cualquier persona detener a otra durante la comisión de un delito o justo al consumarse éste, a unque se han crea do formas de cuasiflagrancia. Así, pues, cierto es que si en una inspección de las multicitadas, efectivamente, se encuentra "algo" se estaría hablando de una forma de flagrancia. Al respecto, la Suprema Corte ha pronunciado la siguiente tesis:

Registro No. 217303

FAGRANTE DEUTO, NO SE RESTRINGE LA UBERTAD DE TRANSTO TRATANDOSE DE.

Si la detención del inculpado de un delito (en el caso contra la salud) obedece a la intercepción que los elementos militares hic ieron del automóvil que conducía cuando se desplazaba en el tramo de la carretera donde se encontraba establecida la guardia, la captura así hecha, no es conculc atoria de lo establecido por el artíc ulo 11 constitucional, ya que tal retención encuentra su justificación legal en que las autoridades encargadas de practicar diligencias de Policía Judicial en auxilio de la representación social, no están impedidas para interceptar el vehículo relativo cuando, como en el caso, se trate de flagrante delito, sin que con ello se transgreda la garantía de libre tránsito tutelada por el precepto constitucional aludido. SEGUNDO TRIBUNAL COLEGIADO DEL OCTAVO CIRCUITO.

Amparo directo 317/92. Clemente Lozano Cortez. 19 de noviembre de 1992. Unanimidad de votos. Ponente: Enrique Rodríguez Olmedo. Secretaria: Mercedes Rodarte Magdaleno.

Con el criterio anterior queda demostrado que con los puntos de revisión establecidos en la actualidad no tienen los fines enuncia dos en el artículo 11 de la ley fundamental. Por otra parte, la misma resolución invita a pensar que las autoridades jurisdiccionales federales desconocen lo que ocurre en el mundo real, en el que se "siembran" objetos o instrumentos de delitos para inculpar a alguien, se llevan a 
cabo abusos graves, o se ocasionan caos viales que se pueden medir en kilómetros.

Es cierto. Se pueden lograr detenciones (que lastimosamente son excepcionales y, generalmente, no importantes) pero, ¿a costa de qué? De pasar por el intemacionalmente reconocido principio de presunción de inocencia, vulnerar demás derechos humanos, entorpecer el tránsito y actividades cotidianas, en ocasiones urgentes, de cualquier ciudadano.

Ahora, en una especie de redención de nuestro máximo tribunal nacional, se emitió la jurisprudencia bajo el rubro "TRANSITO, REGLAMENTO DE, DEL DISTRITO FEDERAL INCONSTITUCIONALDAD", registro 253317, en el que se tacha de inconstitucional un reglamento de tránsito (hecho, obviamente, por el Poder Ejecutivo) en el que se interesen derechos fundamentales y garantías individuales, pues un ordenamiento con estas caracteństicas podría ser emitido únicamente por el Congreso (cabe destacar que dicha problemática es padecida por gran cantidad de municipios en el país). Sin embargo, en el contenido de dicha resolución encontramos que: (...) Al respecto, este tribunal considera que cuando el contenido de la reglamentación puede afectar en forma sustancial derechos constituciona Imente protegidos de los gobemados, como lo son, por ejemplo, la libertad de trabajo o de comercio (artíc ulo 5o.), o su vida, libertad, propiedades, posesiones, derecho, familia, domicilio (artículos 14 y 16), etcétera, esas cuestiones no pueden ser materia de afectación por un reglamento autónomo (sin ley a reglamentar) del presidente de la República, pues éste estanía ejerciendo facultades legislativas y reuniendo dos poderes en uno. En cambio, la materia del reglamento sí puede dar lugar a un mero reglamento autónomo de buen gobiemo cuando no regula ni afecta en forma sustancial los derechos antes señalados sino que se limita a dar disposic iones sobre cuestiones secundariasque no los vienen a coartar.

Con lo anterior, además de desa creditar tota Imente los puntos de revisión impuestos por corporaciones policíacas o dependencias del ejecutivo de cualquier nivel, se invalidan los operativos y demás implementados recientemente, ya que no se ha seguido, en ningún 
caso, el procedimiento de suspensión de garantías individua les previsto en el artíc ulo 29 de la CPEUM.

La postura tomada en contra de estas prácticas es respaldada, incluso, por miembros del Congreso de la Unión, lo cual se acredita con lo siguiente: CON PUNTO DE ACUERDO, POR EL QUE SE EXHORTA A LA SEDENA Y A LA PGR A SUSPENDER LA REVISIÓN DE LOS TRAMOS CARRETEROS EN SALAMAYUCA, CHIHUAHUA, SUSC RITA POR DIPUTADOS DE DIVERSOS GRUPOS PARLAMENTARIOS

\section{CONSIDERACIONES}

Estos retenes carreteros que existen en toda la República Mexicana son inconstitucionales, porque los efectivos militares y la Procuraduńa General de la República están entorpeciendo el desplazamiento de automóviles en las carreteras correspondientes, y están actuando sin orden escrita de la autoridad competente, ignorando el artículo 16 de la Constitución. De tal manera que esa situación de inconstitucionalidad obedece a la grave situación por la que no solamente Chihuahua, sino muchos estados de la república, están pasando en este momento, pero desde un punto de vista estrictamente constitucional.

Cito el artículo 129: "Solamente habrá comandancias militares fijas y permanentes en los castillos, fortalezas y almacenes que dependan inmediatamente del gobiemo de la unión, o en los campamentos, cuarteles o depósitos que, fuera de las poblaciones, estableciere para la estación de tropas".

\section{Punto de Acuerdo}

De urgente y obvia resolución.

Único. La LX Legislatura de la honorable Cámara de Diputados exhorta a la Secretaría de la Defensa Nacional y a la Procuraduńa General de la República a suspender el Precos Salamayuca, en el estado de Chihuahua, que no contribuye eficazmente al combate del tráfico de drogas y armas, y sí propicia las violaciones de los derechos humanos, la comupción y la impunidad.

Dado en el Palacio Legislativo de San Lázaro, a los 21 días de diciembre de 2006.

Asimismo, se cuenta también con la opinión convergente de la Comisión de Derechos Humanos, de la cual nos permitimos incluir un extracto: 


\section{REVISIONES PRECAUTORIASY REIENES. SON ILEGALES}

RECOMENDACIÓN DICTADA EN EL EXPEDIENTE 41/2002 POR LA COMISIÓN DE DERECHOSHUMANOS DEL ESTADO DE NAYARIT

En la resolución de dos expedientes acumulados cuyos motivos fueron, a su vez, estimados coincidentes con los de quejas previamente resueltas, la Comisión estatal de Derechos Humanos efectuó la siguiente consideración que se sintetiza: "En la mayoría de los casos planteados en estas recomendaciones, los policías informaron que al registrar al ciudadano por "sospechoso" se le encontró droga o en posesión de un arma; con esto se trató de justificar su detención. Una gran parte de los afectados alegaron que la droga o el arma les fue "sembrada"; la falta de testigos hace que pocas veces se comoboren estos hechos. Lo anterior también puede ocumir en los llamados retenes, pues el ciudadano queda al libre arbitrio de la autoridad una vez que es detenido en su tránsito. El fin no justifica los medios; en un Estado democrático de derecho hay reglas claras, fijadas de antemano por las leyes, que determinan lo que debe hacerse en caso de descubrir la comisión de un delito.

(...)

Con las revisiones precautorias se violaron los derechos a la libertad de tránsito, legalidad y seguridad juńdica, y el principio de presunción de inocencia, garantías que están consagradas en los artíc ulos 11, 14 y 16 de la Constitución Polític a de los Estados Unidos Mexic a nos y los a rtíc ulos 9․ Y 14.2 del I Pac to Intemacional de Derechos Civiles y Polític os, 7ㅇ, puntos 1, 2 y 3 y 8․ Punto 2 de la Convención Americana sobre Derechos Humanos."

De lo que se ha vertido en esta comunicación, resulta claro que es indispensable y apremiante que el Estado implemente acciones contra la delincuencia que sean efectivas y eficientes y que, además, sean respetuosas de derechos humanos tan básicos como la dignidad, privacidad y libertad, así como de principios fundamentales como el de presunción de inocencia. 
Referencias:

- Constitución Política de los Estados Unidos Mexicanos comenta da y concordada, tomo I. 19ạ edición. Colaborador. Andrade Sánchez, Eduardo. Editorial Pomúa/Universidad Nacional Autónoma de México. México, 2006.

- Manual del justiciable, materia penal. Primera Edición. Poder Judicial de la Federación. México, 2003.

- Portales de Intemet: www.scjn.gob.mx, www.cndh.org.mx, www.congreso.gob.mx, www.jurid ic a s.una m.mx 